\title{
Prediction of recovery from supplementary motor area syndrome after brain tumor surgery: preoperative diffusion tensor tractography analysis and postoperative neurological clinical course
}

\author{
Kazunori Oda, MD, ${ }^{1}$ Fumio Yamaguchi, MD, PhD, ${ }^{2}$ Hiroyuki Enomoto, MD, ${ }^{1}$ Tadashi Higuchi, MD, ${ }^{1}$ \\ and Akio Morita, MD, PhD'1
}

Departments of ${ }^{1}$ Neurological Surgery and ${ }^{2}$ Neurosurgery for Community Health, Nippon Medical School, Bunkyo-Ku, Tokyo, Japan

\begin{abstract}
OBJECTIVE Previous studies have suggested a correlation between interhemispheric sensorimotor networks and recovery from supplementary motor area (SMA) syndrome. In the present study, the authors examined the hypothesis that interhemispheric connectivity of the primary motor cortex in one hemisphere with the contralateral SMA may be important in the recovery from SMA syndrome. Further, they posited that motor cortical fiber connectivity with the SMA is related to the severity of SMA syndrome.

METHODS Patients referred to the authors' neurological surgery department were retrospectively analyzed for this study. All patients with tumors involving the unilateral SMA region, without involvement of the primary motor area, and diagnosed with SMA syndrome in the postoperative period were eligible for inclusion. Preoperative diffusion tensor imaging tractography (DTT) was used to examine the number of fiber tracts (NFidx) connecting the contralateral SMA to the ipsilateral primary motor area via the corpus callosum. Complete neurological examination had been performed in all patients in the pre- and postoperative periods. All patients were divided into two groups: those who recovered from SMA syndrome in $\leq 7$ days (early recovery group) and those who recovered in $\geq 8$ days (late recovery group). Differences between the two groups were assessed using the Student t-test and the chi-square test.
\end{abstract}

RESULTS Eleven patients (10 men, 1 woman) were included in the study. All patients showed transient postoperative motor deficits because of SMA syndrome. Tractography data revealed NFidx from the contralateral SMA to the ipsilateral primary motor area via the corpus callosum. The mean tumor volume (early 27.87 vs late $50.91 \mathrm{~cm}^{3}, \mathrm{p}=0.028$ ) and mean NFidx (early 8923.16 vs late $4726.4, p=0.002$ ) were significantly different between the two groups. Fisher exact test showed a significant difference in the days of recovery from SMA syndrome between patients with an NFidx $>8000$ and those with an NFidx $<8000$.

CONCLUSIONS Diffusion tensor imaging tractography may be useful for predicting the speed of recovery from SMA syndrome. To the authors' knowledge, this is the first DTT study to identify interhemispheric connectivity of the SMA in patients with brain tumors.

https://thejns.org/doi/abs/10.3171/2017.12.FOCUS17564

KEYWORDS supplementary motor area syndrome; diffusion tensor imaging; tractography; brain tumor; neurosurgery

$\mathrm{T}$ HE supplementary motor area (SMA) is an eloquent area that plays an important role in the moving, planning, and learning of complicated actions, as well as the initiation of speech in the dominant hemisphere. The SMA is located in Brodmann area 6 and is defined by a single cortical field anterior to the leg representation of the primary motor cortex (PMC) along the medial aspect of the cerebral hemisphere down to the cingulate sulcus. ${ }^{16,19}$ The SMA is composed of the SMA proper and the pre-SMA. The SMA proper is involved in

ABBREVIATIONS DTI = diffusion tensor imaging; DTT = DTI tractography; NFidx = number of fiber tracts; $\mathrm{PMC}=$ primary motor cortex; $\mathrm{ROI}=$ region of interest; $\mathrm{SMA}=$ supplementary motor area.

SUBMITTED August 31, 2017. ACCEPTED December 11, 2017.

INCLUDE WHEN CITING DOI: 10.3171/2017.12.FOCUS17564. 
planning, initiating, and coordinating complicated actions and in helping to maintain an erect posture, whereas the pre-SMA is involved in the cognitive aspects of complicated actions. ${ }^{6,7}$

The SMA has a high frequency of brain tumors, including up to $10 \%$ of de novo glioblastomas and $27 \%$ of lowgrade gliomas. ${ }^{4}$ Thus, the SMA is often a surgical target for tumor removal, and brain surgery in this area can lead to SMA syndrome. This syndrome was first reported to involve contralateral transient akinesia and mutism when the lesion was in the dominant hemisphere. ${ }^{11,12}$ Resections of the SMA can cause immediate postoperative motor and speech deficits, which can resolve spontaneously and completely within days to months., ${ }^{2,5}$ Thus, it is important for neurosurgeons to determine the anatomical and functional limits of an SMA resection and to identify SMA syndrome and monitor its course of recovery. However, the mechanism of recovery of SMA syndrome is poorly understood, although the contralateral SMA is thought to complement the function of the affected SMA. ${ }^{1}$ Interestingly, Vassal et al. reported evidence of plasticity of the SMA, with large-scale modifications of the sensorimotor network, suggesting that interhemispheric connectivity may correlate with SMA syndrome recovery. ${ }^{18}$

In the present study, we hypothesized that interhemispheric connectivity of the PMC in one hemisphere with the contralateral SMA may play an important role in the recovery from SMA syndrome and that cortical fiber connections of the SMA may be associated with SMA syndrome recovery. To examine this hypothesis, we assessed preoperative diffusion tensor imaging (DTI) tractography (DTT) to determine the number of fibers extending from the contralateral SMA to the ipsilateral PMC, as well as the postoperative course of SMA syndrome, in patients with SMA syndrome following tumor removal.

\section{Methods \\ Patients}

Patients referred to neurological surgery from 2014 to 2016 were retrospectively analyzed for this study. All patients were confirmed to have brain tumor involving the unilateral SMA, without involvement of the PMC, and a diagnosis of SMA syndrome in the postoperative period. Informed consent was obtained from all individual participants included in this study.

\section{Clinical Evaluation}

For all patients, complete neurological examinations had been performed by 3 neurosurgeons preoperatively, immediately after surgery, 24 hours after surgery, and 3 months after surgery. Neurological examinations included consciousness, speech abilities, handedness, and manual muscle testing of both the upper and lower extremities. Manual muscle testing was performed as described in Daniels and Worthingham's Muscle Testing. ${ }^{8}$

\section{Magnetic Resonance Imaging}

Magnetic resonance imaging was performed preoperatively and at 24 hours and 3 months after surgery. Images were acquired on a modified Siemens Magnetom Skyra
3-T scanner (Siemens Healthcare), including a DTI sequence using dual echo-planar imaging (axial slices 40, TR 15,000 msec, TE set to minimum, slice thickness 3.5 $\mathrm{mm}$, matrix $160 \times 160$, FOV $24 \mathrm{~cm}^{2}$, b values $=0$ and $1000 \mathrm{sec} / \mathrm{mm}^{2}$ applied in 16 noncollinear directions, scan time 4 minutes and 30 seconds).

\section{Preoperative DTT Analysis}

Diffusion tensor imaging tractography analysis using DTI data was performed with a surgical navigation system (StealthStation S7, Medtronic). Standard deterministic streamline DTT was performed with StealthViz software (Medtronic) using a fractional anisotropy threshold of 0.2 and a DTI maximum turning angle of $100^{\circ}$. Using DTT fiber data, we assessed the number of fibers between two distal seed regions of interest (ROIs) that started from the contralateral SMA and projected to the ipsilateral PMC via the corpus callosum. These ROIs were identified on MRI using the method described by Berger et al. ${ }^{3}$ All streamlines passing through the ROIs were retained. No additional tract editing was performed. As DTT analysis involves tracking the voxels of water diffusion signal, we defined these voxel numbers as NFidx (number of fiber tracts) and counted the number of target fibers. ${ }^{9}$

\section{Preoperative and Postoperative MRI Analysis}

Volumetric assessment of tumors on both preoperative and postoperative scans was performed manually using StealthViz software (Medtronic).

\section{Surgical Procedures}

Intraoperative brain mapping by cortical electrical stimulation was performed during surgery to detect and preserve the PMC, while direct subcortical stimulation was performed to preserve the pyramidal tract pathway. ${ }^{20,21}$ In all cases, the SMA was gross totally resected. Total resection was confirmed by postoperative radiological studies.

\section{Statistical Analysis}

Patients were divided into those who recovered from SMA syndrome in $\leq 7$ days after surgery (early recovery group) and those who recovered in $\geq 8$ days after surgery (late recovery group). Differences between the two groups were assessed using the Student t-test and the chi-square test. Statistical significance was defined as $p<0.05$. All statistical analyses were performed using the Excel statistical software package (Ekuseru-Toukei 2015, Social Survey Research Information Co., Ltd.).

\section{Results}

\section{Characteristics of the Study Patients}

Eleven patients (10 men, 1 woman; 41-76 years of age) were included in this study. All patients were right-handed. Five patients had a tumor in the right hemisphere and 6 patients in the left hemisphere. Five lesions were in the pre-SMA, located anterior to the SMA proper. On admission, 2 patients had motor aphasia and 9 had unilateral focal motor seizures. Only 1 patient had motor deficit at the beginning of the clinical course (Table 1). 
TABLE 1. Clinical characteristics of the 11 right-handed patients included in this study

\begin{tabular}{|c|c|c|c|c|c|c|c|c|c|c|c|}
\hline Case No. & 1 & 2 & 3 & 4 & 5 & 6 & 7 & 8 & 9 & 10 & 11 \\
\hline Age in yrs & 66 & 61 & 49 & 68 & 41 & 58 & 62 & 60 & 66 & 76 & 64 \\
\hline Sex & $M$ & $\mathrm{~F}$ & $M$ & $M$ & $M$ & $M$ & $M$ & $M$ & $M$ & $M$ & $M$ \\
\hline Hemisphere & $\mathrm{Lt}$ & Rt & $\mathrm{Lt}$ & Rt & $\mathrm{Lt}$ & $\mathrm{Lt}$ & Rt & Rt & $\mathrm{Lt}$ & Rt & $\mathrm{Lt}$ \\
\hline Tumor location & Pre-SMA & Pre-SMA & $\begin{array}{l}\text { SMA } \\
\text { proper }\end{array}$ & $\begin{array}{l}\text { SMA } \\
\text { proper }\end{array}$ & Pre-SMA & Pre-SMA & Pre-SMA & $\begin{array}{l}\text { SMA } \\
\text { proper }\end{array}$ & $\begin{array}{l}\text { SMA } \\
\text { proper }\end{array}$ & $\begin{array}{l}\text { SMA } \\
\text { proper }\end{array}$ & $\begin{array}{l}\text { SMA } \\
\text { proper }\end{array}$ \\
\hline Clinical features & $\begin{array}{l}\text { Rt motor } \\
\text { sei- } \\
\text { zures }\end{array}$ & $\begin{array}{l}\text { Lt motor } \\
\text { sei- } \\
\text { zures }\end{array}$ & $\begin{array}{l}\text { Rt motor } \\
\text { sei- } \\
\text { zures }\end{array}$ & $\begin{array}{l}\text { Lt motor } \\
\text { sei- } \\
\text { zures }\end{array}$ & $\begin{array}{l}\text { Motor apha- } \\
\text { sia }\end{array}$ & $\begin{array}{l}\text { Rt motor } \\
\text { sei- } \\
\text { zures }\end{array}$ & $\begin{array}{l}\text { Lt motor } \\
\text { sei- } \\
\text { zures }\end{array}$ & $\begin{array}{l}\text { Lt motor } \\
\text { sei- } \\
\text { zures }\end{array}$ & $\begin{array}{l}\text { Motor } \\
\text { apha- } \\
\text { sia }\end{array}$ & $\begin{array}{l}\text { Lt motor } \\
\text { sei- } \\
\text { zures }\end{array}$ & $\begin{array}{l}\text { Rt motor } \\
\text { sei- } \\
\text { zures }\end{array}$ \\
\hline \multicolumn{12}{|l|}{ Preop evaluation } \\
\hline Aphasia & No & No & No & No & Yes & No & No & No & Yes & No & No \\
\hline Facial motor deficit & No & No & No & No & No & No & No & No & No & No & No \\
\hline UE motor deficit & No & No & No & No & No & No & No & No & No & No & No \\
\hline LE motor deficit & No & Yes & No & No & No & No & No & No & No & No & No \\
\hline Preop tumor vol $\left(\mathrm{cm}^{3}\right)$ & 17.5 & 52.2 & 34.2 & 38.5 & 24.8 & 77 & 35.7 & 25.9 & 55.7 & 44.8 & 15.4 \\
\hline Pathological diagnosis & GBM & GBM & LGG & $\begin{array}{l}\text { Metas- } \\
\text { tasis } \\
\text { (lung) }\end{array}$ & GBM & Malg & LGG & LGG & GBM & GBM & $\begin{array}{l}\text { Metas- } \\
\text { tasis } \\
\text { (lung) }\end{array}$ \\
\hline $\begin{array}{l}\text { Postop neurological } \\
\text { course }\end{array}$ & $\begin{array}{c}\text { Transient } \\
\text { motor } \\
\text { deficit }\end{array}$ & $\begin{array}{c}\text { Transient } \\
\text { motor } \\
\text { deficit }\end{array}$ & $\begin{array}{c}\text { Transient } \\
\text { motor } \\
\text { deficit }\end{array}$ & $\begin{array}{c}\text { Transient } \\
\text { motor } \\
\text { deficit }\end{array}$ & $\begin{array}{l}\text { Transient mo- } \\
\text { tor deficit, } \\
\text { transient } \\
\text { aphasia }\end{array}$ & $\begin{array}{c}\text { Transient } \\
\text { motor } \\
\text { deficit }\end{array}$ & $\begin{array}{c}\text { Transient } \\
\text { motor } \\
\text { deficit }\end{array}$ & $\begin{array}{c}\text { Transient } \\
\text { motor } \\
\text { deficit }\end{array}$ & $\begin{array}{c}\text { Transient } \\
\text { motor } \\
\text { deficit }\end{array}$ & $\begin{array}{c}\text { Transient } \\
\text { motor } \\
\text { deficit }\end{array}$ & $\begin{array}{r}\text { Transient } \\
\text { motor } \\
\text { deficit }\end{array}$ \\
\hline $\begin{array}{l}\text { Days of recovery from } \\
\text { SMAS }\end{array}$ & 7 & 30 & 7 & 7 & 15 & 15 & 5 & 5 & 9 & 8 & 5 \\
\hline NFidx & 7252 & 3449 & 8825 & 8879 & 5188 & 5857 & 8474 & 11,767 & 2374 & 6764 & 8342 \\
\hline
\end{tabular}

GBM = glioblastoma multiforme; LE = lower extremity; $L G G$ = low-grade glioma; Malg = malignant lymphoma; SMAS = SMA syndrome; UE = upper extremity.

In all cases, the postoperative tumor volume was $0 \mathrm{~cm}^{3}$, resection percentage was $100 \%$, and SMA resection was total.

\section{DTT Streamline and NFidx}

In all cases, the target streamlines, which started from the contralateral SMA and projected to the ipsilateral PMC, were found in each DTT analysis. Sagittal, coronal, and axial DTT images from case 1 are shown in Fig. 1A-C. Merging of these 3 images is shown in Fig. 1D. The target streamline in the 3D images is shown in Fig. $1 \mathrm{E}$. The NFidx was counted, with a range of 3449-11,767 (Table 1).

\section{Surgical Procedures and Clinical Evaluation}

At surgery, all cases underwent total resection of the tumor and SMA, which was confirmed by postoperative enhanced MRI. The mean preoperative tumor volume ranged from 15.4 to $77.0 \mathrm{~cm}^{3}$. All tumors were histologically confirmed after each surgery. Five cases were confirmed as glioblastoma, 3 as low-grade glioma, 2 as metastasis from lung carcinoma, and 1 as malignant lymphoma (Table 1). Immediately after surgery, all patients exhibited severe motor deficits in the contralateral extremities. Postoperative diffusion-weighted MRI revealed no evidence of postoperative stroke. After surgery, patients were treated with appropriate therapy, including steroids and antihydropic agents. In the postoperative period, the motor deficits improved in all cases, ultimately reaching preoperative levels. The period of recovery from SMA syndrome ranged from 5 to 30 days. After the recovery from motor deficits, no cases showed new neurological deficits up to 3 months after surgery. The pre- and postoperative MR images in case 1 are shown in Fig. 2.

\section{Univariate Analysis}

We compared basic characteristics between the early recovery group and late recovery group. There were no differences in age, sex, affected hemisphere, or tumor location between the groups. However, there were significant differences in the mean tumor volume (early 27.87 vs late $50.91 \mathrm{~cm}^{3}, \mathrm{p}=0.028$ ) and mean NFidx (early 8923.16 vs late $4726.4, p=0.002$ ) between the groups (Table 2 ). Fisher exact test showed a significant difference in the days of recovery from SMA syndrome between patients with an NFidx $<8000$ and those with an NFidx $>8000$ (Table 3).

\section{Discussion}

The aim of the present study was to identify the connectivity between two distal seed ROIs using DTT in SMA syndrome patients and to evaluate its clinical course. The extent of postoperative motor deficit is considered to be related to the extent of SMA resection since SMA syndrome is observed in all cases of total SMA removal but is not observed in cases of partial removal. ${ }^{2}$ Other studies have also reported that motor deficit occurs more frequently 

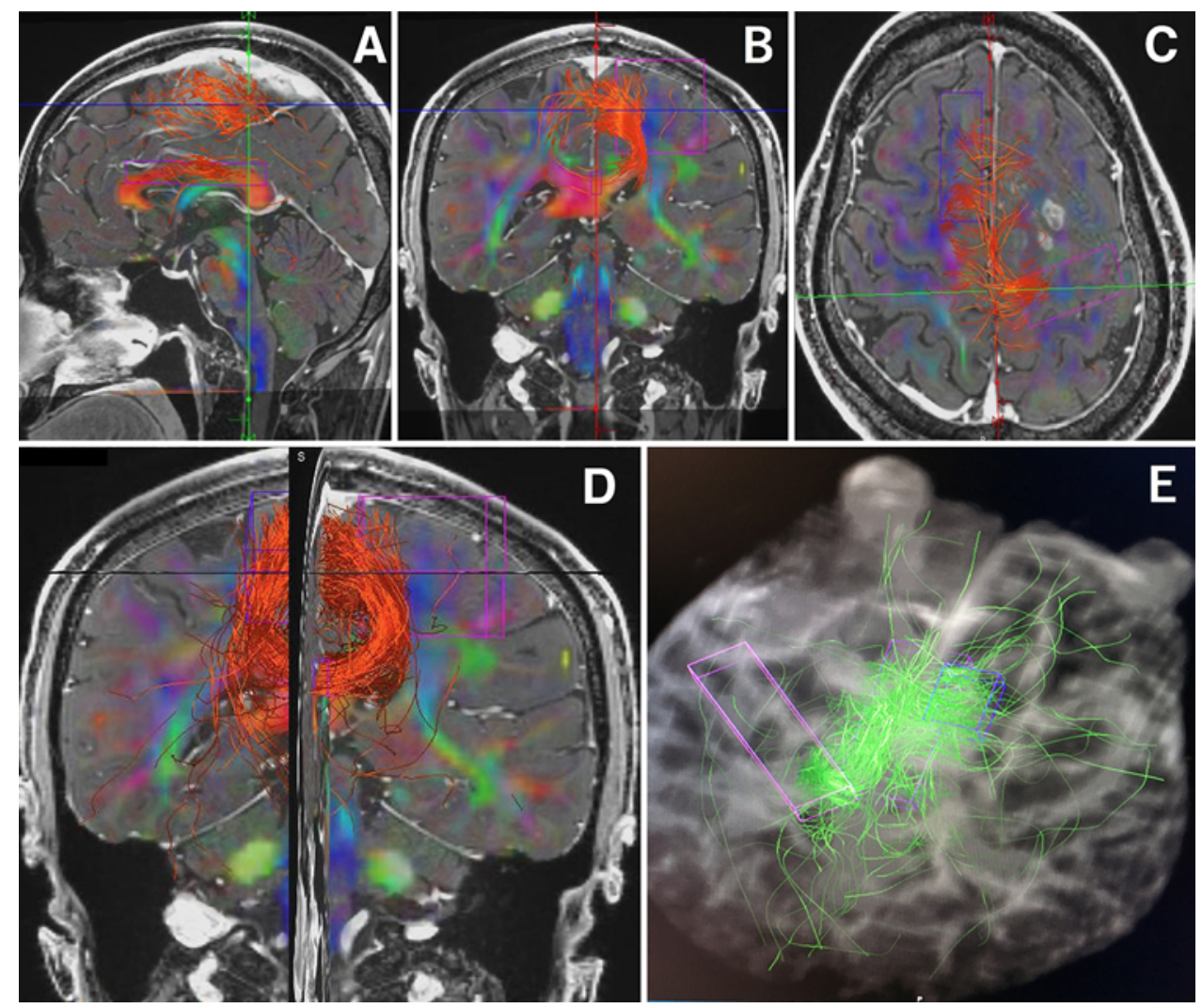

FIG. 1. Case 1. Sagittal, coronal, and axial DTT images. A-C: The orange streamline represents the target streamline. The purple box represents the ROI in the corpus callosum; pink box, the ROI in the unilateral PMC; and blue box, the ROI in the contralateral SMA. D: Merged images of A-C. E: Target streamline (green) in 3D images.
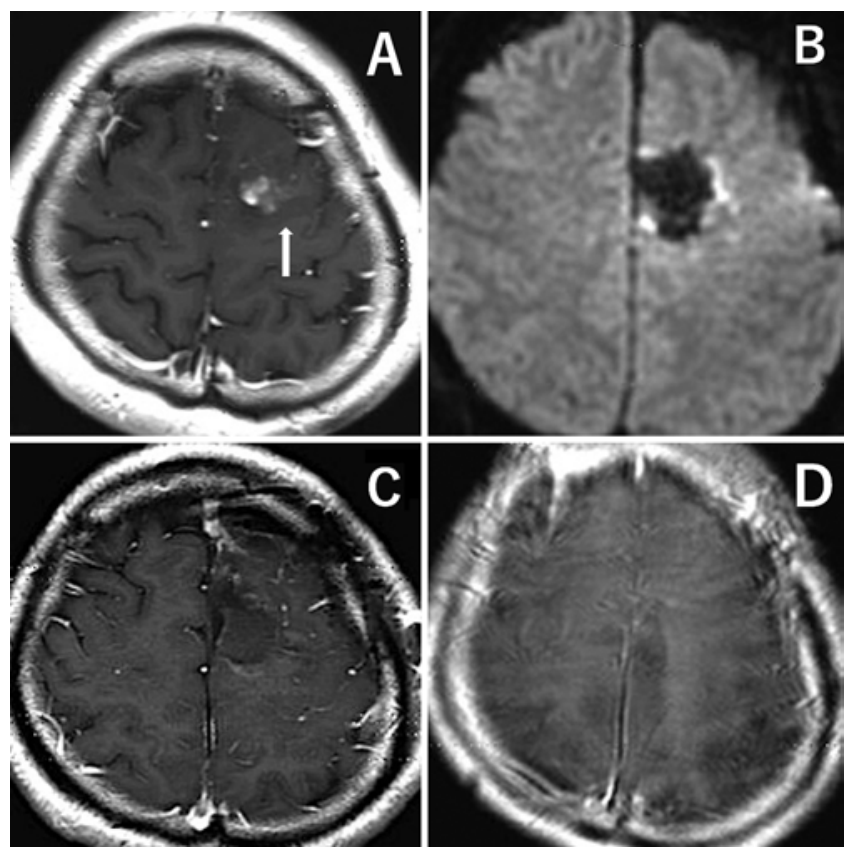

FIG. 2. Case 1. A: Preoperative contrast-enhanced image showing tumor located in the pre-SMA, which is anterior to the prefrontal gyrus (arrow). B and C: Diffusion-weighted image and contrast-enhanced image obtained on postoperative day 1 showing no postoperative hemorrhage or infarction. D: Contrast-enhanced image obtained at 3 months after surgery demonstrating no recurrence or other lesions. when the resection extends into the caudal SMA.10,22 Thus, in the present study, we selected cases with total SMA resection. In one of our cases, a postoperative speech disorder involved transient aphasia, followed by continuous improvement in speech fluency, similar to that reported in Sailor et al. ${ }^{17}$ It has been suggested that only the dominant-hemisphere SMA is involved in language function, ${ }^{15}$ although we had only one case with postoperative transient aphasia despite total SMA resection in the dominant hemisphere. Resection of the SMA in the nondominant hemisphere has also been reported to cause speech dysfunction. ${ }^{13}$ Thus, the mechanism of transient motor aphasia in SMA syndrome remains unclear. Interestingly, the main symptoms after surgery were seizures and almost no deficit among all patients. Because of the very different histologies, it would seem that the severity of some seizures was related to the amount of time a patient had experienced symptoms. Further investigations are needed to validate the symptomatic relationships.

\section{Target Connections}

We successfully identified the target connections traversing from the contralateral SMA to the ipsilateral PMC area via the corpus callosum in each DTT analysis. Interhemispheric connectivity is both inversely correlated with preoperative deficit and positively correlated with postoperative recovery from SMA syndrome. ${ }^{14,18}$ Our data also 
TABLE 2. Comparison of patient characteristics between the early and late recovery groups

\begin{tabular}{lcccc}
\hline \multicolumn{1}{c}{ Parameter } & All & Early & Late & $p$ Value \\
\hline No. of patients & 11 & 6 & 5 & 0.858 \\
\hline Mean age in yrs (SD) & $61.0(9.423)$ & $61.5(6.745)$ & $60.4(12.818)$ & 0.421 \\
\hline No. of males (\%) & $10(90.9)$ & $6(100)$ & $4(80.0)$ & 0.482 \\
\hline No. in rt hemisphere (\%) & $5(45.4)$ & $3(50.0)$ & $3(40.0)$ & 0.327 \\
\hline No. tumors in pre-SMA (\%) & $5(45.4)$ & $2(33.3)$ & $50.91(18.870)$ & $0.028^{*}$ \\
\hline Mean preop tumor vol in cm ${ }^{3}(\mathrm{SD})$ & $38.34(18.31)$ & $27.87(9.811)$ & $4726.4(1789.46)$ & $0.002^{*}$ \\
\hline Mean NFidx (SD) & $7051.9(2712.6)$ & $8923.16(1512.04)$ & &
\end{tabular}

suggest that the SMA on the unaffected side may contribute to the sensorimotor network and actual connectivity, as a substitute for the resected SMA. To our knowledge, this is the first DTT study to identify interhemispheric connectivity of the SMA in patients with brain tumors. However, anatomical analysis of these connections has not been reported, and further studies examining the neural fibers connecting these regions are required to support our hypothesis.

\section{Tumor Volume and NFidx Findings}

In the present study, the mean tumor volume was significantly larger in the late recovery group than in the early recovery group. To the best of our knowledge, there are no previous reports about the correlation between tumor volume and severity of postoperative SMA syndrome. Our findings suggest that a larger tumor size may prolong the recovery from postoperative SMA syndrome, and this may occur because of postoperative perifocal edema or postoperative motor seizures by surgical stimulation of the PMC area. We also found that the mean NFidx was significantly higher in the early recovery group than in the late recovery group. Furthermore, the Fisher exact test showed that the NFidx can be divided at 8000 to identify the early recovery (within 7 days) and late recovery (more than 8 days) periods. These data suggest that NFidx may contribute to the recovery from postoperative SMA syndrome. Previous functional MRI studies have reported an increase in interhemispheric connectivity between the primary sensorimotor cortex ipsilateral to tumor and the contralateral SMA, simultaneous with motor recovery. ${ }^{18}$ Our data also suggest that the extent of fiber connection is related to the recovery from SMA syndrome.

TABLE 3. Comparison of patients whose NFidx is $<8000$ or $>8000$, between the early and late recovery groups

\begin{tabular}{cccc}
\hline NFidx/Recovery & Early & Late & Total \\
\hline$>8000$ & 5 & 0 & 5 \\
\hline$<8000$ & 1 & 5 & 6 \\
\hline Total & 6 & 5 & 11 \\
\hline
\end{tabular}

Significant difference in the days of recovery from SMA syndrome between patients with an NFidx $>8000$ and those with an NFidx $<8000(p=0.0152$, Fisher exact test).

\section{Study Limitations}

There are some limitations to our study. First, deterministic DTI-based tractography is not a state-of-the-art technique and cannot resolve fiber crossings within image voxels. Second, there is a potential confounding effect of perilesional edema in DTT performed in proximity to tumors given that interstitial edema can blur DTI data and thus terminate fiber tracking. Interestingly, the two patients with the lowest NFidx had glioblastoma, which typically exhibits marked perilesional edema and thus is likely to interfere with the tracking procedure. Furthermore, DTT may also be affected by infiltration. The confounding effect of perilesional edema could be caused by tumor infiltration. Thus, as we mentioned above, in comparison to low-grade lesions, the fiber tract integrity around highgrade lesions or glioblastoma is disturbed, possibly only allowing for suboptimal estimation of the connectivity. Further investigations are needed to validate the relationships between the infiltrative zone and the reliability of fiber analysis. Finally, it is possible that the postoperative motor deficits were unrelated to the postoperative SMA syndrome, but rather were associated with other causes, such as postoperative edema of the PMC area.

\section{Conclusions}

We performed the first DTT analysis to identify interhemispheric connectivity of the SMA in patients with brain tumors and found a statistical relationship between the extent of fiber connections and clinical recovery from SMA syndrome. These findings may be useful for the future prediction of recovery from SMA syndrome and suggest a relationship between cortical fiber connections of the SMA and the degree of deficit in SMA syndrome. Further studies examining microanatomical fiber connectivity are required.

\section{Acknowledgments}

We thank Edanz Group for editing a draft of this manuscript.

\section{References}

1. Acioly MA, Cunha AM, Parise M, Rodrigues E, Tovar-Moll F: Recruitment of contralateral supplementary motor area in functional recovery following medial frontal lobe surgery: an fMRI case study. J Neurol Surg A Cent Eur Neurosurg 76:508-512, 2015 
2. Anber K: Post-operative supplementary motor area syndrome. Med J Cairo Univ 80:385-389, 2012

3. Berger MS, Cohen WA, Ojemann GA: Correlation of motor cortex brain mapping data with magnetic resonance imaging. J Neurosurg 72:383-387, 1990

4. Duffau H, Capelle L: Preferential brain locations of lowgrade gliomas. Cancer 100:2622-2626, 2004

5. Duffau H, Lopes M, Denvil D, Capelle L: Delayed onset of the supplementary motor area syndrome after surgical resection of the mesial frontal lobe: a time course study using intraoperative mapping in an awake patient. Stereotact Funct Neurosurg 76:74-82, 2001

6. Gerloff C, Corwell B, Chen R, Hallett M, Cohen LG: Stimulation over the human supplementary motor area interferes with the organization of future elements in complex motor sequences. Brain 120:1587-1602, 1997

7. Goldberg G: Supplementary motor area structure and function: review and hypothesis. Behav Brain Sci 8:567-588, 1985

8. Hislop H, Avers D, Brown M: Daniels and Worthingham's Muscle Testing, 9th ed. St. Louis: Elsevier Saunders, 2014

9. Ius T, Turella L, Pauletto G, Isola M, Maieron M, Sciacca G, et al: Quantitative diffusion tensor imaging analysis of lowgrade gliomas: from preclinical application to patient care. World Neurosurg 97:333-343, 2017

10. Krainik A, Lehéricy S, Duffau H, Vlaicu M, Poupon F, Capelle L, et al: Role of the supplementary motor area in motor deficit following medial frontal lobe surgery. Neurology 57:871-878, 2001

11. Laplane D, Talairach J, Meininger V, Bancaud J, Bouchareine A: Motor consequences of motor area ablations in man. $\mathbf{J}$ Neurol Sci 31:29-49, 1977

12. Laplane D, Talairach J, Meininger V, Bancaud J, Orgogozo JM: Clinical consequences of corticectomies involving the supplementary motor area in man. J Neurol Sci 34:301-314, 1977

13. Nelson L, Lapsiwala S, Haughton VM, Noyes J, Sadrzadeh $\mathrm{AH}$, Moritz CH, et al: Preoperative mapping of the supplementary motor area in patients harboring tumors in the medial frontal lobe. J Neurosurg 97:1108-1114, 2002

14. Otten ML, Mikell CB, Youngerman BE, Liston C, Sisti MB, Bruce JN, et al: Motor deficits correlate with resting state motor network connectivity in patients with brain tumours. Brain 135:1017-1026, 2012

15. Pai MC: Supplementary motor area aphasia: a case report. Clin Neurol Neurosurg 101:29-32, 1999

16. Penfield W, Welch K: The supplementary motor area of the cerebral cortex; a clinical and experimental study. AMA Arch Neurol Psychiatry 66:289-317, 1951

17. Sailor J, Meyerand ME, Moritz CH, Fine J, Nelson L, Badie $\mathrm{B}$, et al: Supplementary motor area activation in patients with frontal lobe tumors and arteriovenous malformations. AJNR Am J Neuroradiol 24:1837-1842, 2003

18. Vassal M, Charroud C, Deverdun J, Le Bars E, Molino F, Bonnetblanc F, et al: Recovery of functional connectivity of the sensorimotor network after surgery for diffuse low-grade gliomas involving the supplementary motor area. J Neurosurg 126:1181-1190, 2017

19. Woolsey CN, Settlage PH, Meyer DR, Sencer W, Pinto Hamuy T, Travis AM: Patterns of localization in precentral and "supplementary" motor areas and their relation to the concept of a premotor area. Res Publ Assoc Res Nerv Ment Dis 30:238-264, 1952

20. Yamaguchi F, Takahashi H, Teramoto A: Intra-operative detection of motor pathways using a simple electrode provides safe brain tumor surgery. J Clin Neurosci 14:1106-1110, 2007

21. Yamaguchi F, Takahashi H, Teramoto A: Navigation-assisted subcortical mapping: intraoperative motor tract detection by bipolar needle electrode in combination with neuronavigation system. J Neurooncol 93:121-125, 2009

22. Zentner J, Hufnagel A, Pechstein U, Wolf HK, Schramm J: Functional results after resective procedures involving the supplementary motor area. J Neurosurg 85:542-549, 1996

\section{Disclosures}

The authors report no conflict of interest concerning the materials or methods used in this study or the findings specified in this paper.

\section{Author Contributions}

Conception and design: Yamaguchi, Enomoto. Acquisition of data: Oda. Analysis and interpretation of data: Oda, Enomoto. Drafting the article: Oda, Yamaguchi. Critically revising the article: Yamaguchi, Enomoto, Higuchi, Morita. Statistical analysis: Oda. Study supervision: Morita.

\section{Correspondence}

Kazunori Oda: Nippon Medical School, Tokyo, Japan. kazu. nms7023@gmail.com. 